\title{
Changes in age-0 yellow perch habitat and prey selection across a round goby invasion front
}

Christopher J. Houghton ${ }^{a, b, *}$, John Janssen ${ }^{a}$

${ }^{a}$ University of Wisconsin - Milwaukee, School of Freshwater Sciences, 600 E. Greenfield Ave, Milwaukee, Wisconsin 53214, U. S. A.

${ }^{b}$ Current address: University of Wisconsin - Green Bay, Natural and Applied Sciences, 413 Laboratory Sciences Building, Green Bay, Wisconsin 54311, U. S. A.

* Corresponding author. Tel.: 1-920-465-2922

E-mail Address: houghtoc@uwgb.edu 


\section{Abstract}

Round gobies (Neogobius melanostomus) are reported to have negative impacts on benthic invertebrate prey and are now highly abundant throughout most of the Laurentian Great Lakes. This study used the initial spread of round gobies north and south from Milwaukee Harbor as a natural experiment to assess the competitive interactions between age- 0 yellow perch and round gobies in western Lake Michigan. Habitat selection and diet of age-0 yellow perch in relation to round goby abundance were analyzed using fish captured in micro-mesh gillnets in 2006 and 2007 at six study locations from Sheboygan to Wind Point, Wisconsin. An age-0 yellow perch shift in habitat preference from rock to sand was associated with relatively high round goby abundance at rock sites. An increase in round goby catch per unit effort was also correlated with a decrease in benthic prey (chironomid larvae + amphipods) abundance at rock sites and occurrence of these prey items in age- 0 yellow perch stomach contents. Our results suggest age- 0 yellow perch may have undergone local niche shifts as a consequence of competition with round gobies. Further study may help elucidate the causal mechanism behind our observations and determine what effect round gobies are having on the yellow perch population of western Lake Michigan, as a whole.

Keywords: exploitative competition, resource utilization, round goby, yellow perch, Lake Michigan, habitat shift 


\section{Introduction}

Invasions of non-native organisms are altering ecosystems and the Laurentian Great Lakes have had several invaders, e.g. sea lamprey (Petromyzon marinus, a trophically top-down invader) and dreissenid mussels (a middle-out invader), that rendered their ecological communities vastly different than they were a century ago. Among the significant invaders is the round goby (Neogobius melanostomus), which was first detected in 1990 (Jude et al. 1992). Round gobies are associated with dramatic reductions or extirpations of certain native benthic species such as mottled sculpin (Cottus bairdi; Janssen and Jude, 2001, Lauer et al. 2004), and johnny darters (Ethostoma nigrum; Lauer et al. 2004), with other benthic fishes likely at risk (Poos et al. 2010). Mechanisms of extirpation or population reduction by non-indigenous species can be difficult to demonstrate with predation likely the easiest to reveal (e.g. sea lamprey predation on lake trout (Salvelinus namaycush)). Competition is more difficult to demonstrate in part because, a weakened losing competitor may be more vulnerable to predation. For example, Rice et al. (1987) argued that, for bloater (Coregonus hoyi) in the Great Lakes, exploitative competition for zooplankton with alewife (Alosa pseudoharengus) could reduce growth and/or predator escape capability and thus render poor competitors more susceptible to predation.

We use a natural field experiment to demonstrate a general hypothesis that round gobies can compete with yellow perch (Perca flavescens), at least under the conditions of western Lake Michigan. We discuss nuances of western Lake Michigan further in the Discussion but here note that macrophytic vascular vegetation, a common feature of yellow perch habitats in smaller lakes and ponds, are absent from the open coasts of Lake Michigan. Instead, the 
preferred habitat of both round gobies and yellow perch in western Lake Michigan is rock habitat (see Kornis et al., 2012 for a review of round goby ecology and Janssen and Luebke, 2004, Janssen et al., 2005 for yellow perch habitat selection).

One potential consequence of competition, hence a potential test, is niche shifts (competitive displacement) between competing species. Niche shifts have been used to justify competition as the operating mechanism in relatively easily observed organisms such as birds (Diamond, 1970), lizards (Schoener, 1975), and plants (Grace and Wetzel, 1981). Fishes are less easily observed than plants and diurnally active terrestrial vertebrates, but the observational challenge does not mean that niche shifts do not exist. Interspecific competition in fishes has been assessed using nonindigenous species (NIS; sensu Chisolm, 2009) introductions and resulting niche shifts as natural experiments in the Laurentian Great Lakes (Crowder, 1986) as well as the African Great Lakes (Wanink and Witte, 2000). Wanink and Witte (2000) documented niche shifts in habitat selection and prey preferences in dagaa (Rastrineobola argentea), by following the dagaa population before the Nile perch (Lates niloticus) introduction as well as through the Nile perch's spread and population boom in Lake Victoria. In Lake Michigan, Crowder (1986) used the introduction of nonindigenous alewife as a natural experiment to infer competition with bloater. Crowder (1986) theorized that interspecific exploitative competition for zooplankton prey was the driving factor behind observed habitat and prey shifts of bloater after the alewife's introduction.

While observational studies of niche shifts are an important tool to assess interspecific competition in the wild, they lack the ability to distinguish what competitive mechanisms are 
causing observed differences (Matthews, 1998). Experimental manipulation of the densities of competing species and limiting resources in enclosed systems have offered researchers the ability to assess these underlying mechanisms. Studies on interspecific competition between fish species often use experimental ponds (Werner and Hall, 1977) and enclosures (Duncan et al., 2011) that allow species densities and habitats to be manipulated and controlled. Manipulative studies allow researchers to precisely control the factors being assessed. However, mesocosm experiments often do not accurately represent conditions in the wild (ex. unreal fish densities or habitats), hence such enclosure experiments are more likely to show competition than unenclosed experiments (Schoener, 1983). While, on the other hand, studies of competition in the wild, often due to their inherent size and natural variability, are criticized for not controlling enough factors to adequately assess their contribution to an observed response.

The goal of the present study was to use the population density gradient along a round goby invasion front as a natural experiment to assess interspecific competition between round goby and a native species, yellow perch. We focus our study on exploitative competition. However, round gobies are known to be antagonistic towards other species and conspecifics (Dubs and Corkum, 1996; Ray and Corkum, 2001). Interference competition between round gobies and age- 0 yellow perch is also possible, and both forms of competition are not mutually exclusive. Our study was performed during the initial invasion of the round goby to the western shores of Lake Michigan originating at Milwaukee, Wisconsin (pers. comm. Pradeep Hirethota WI DNR, Milwaukee, Wisconsin). Round gobies were first observed in Milwaukee harbor in 1999. They 
were first seen outside of the harbor in 2004 and slowly radiated north and south along the coastline from this initial introduction site (Houghton pers. obs.).

The progression of the round goby invasion presented a unique opportunity to assess changes in two niche dimensions of age-0 yellow perch, habitat and prey, along a gradient of round goby densities in the wild. Previous work using similar sampling methods (micro-mesh gillnets set on rock versus sand substrates) showed a strong site affinity of age-0 yellow perch toward rock substrates (Janssen and Luebke, 2004), which are also the preferred habitat for round gobies (Kornis et al. 2012). Habitat and prey use by age-0 yellow perch occurring with round gobies along the round goby invasion front was used to determine the effect of round gobies on age-0 yellow perch in the wild. Effects of round goby abundance on rock associated benthic invertebrates were also assessed with the goal of determining if competitive displacement of age-0 yellow perch may result as a consequence of exploitative competition for prey. We therefore had three general hypotheses:

Hypothesis 1: Age-0 yellow perch habitat selection changes with increasing numbers of round gobies at rock sites.

Hypothesis 2: There is evidence of exploitative competition: benthic invertebrate abundance at rock sites decreases with increasing round goby densities at rock sites.

Hypothesis 3: Age-0 yellow perch undergo a diet shift: age-0 yellow perch feed on lower amounts of benthic invertebrates when round gobies are present at rock sites.

Competitive displacement in the form of a reduction of habitat or prey use by age- 0 yellow perch as a response to increasing round goby abundance would provide evidence consistent 
with interspecific competition between the two species (hypotheses 1 and 3) while a decrease in benthic invertebrate abundance with round goby invasion may indicate that prey becomes a limiting resource as round goby abundance increases (hypothesis 2).

We also used our data set as an opportunity to assess the variation of both invertebrate prey abundance at rock habitats and the occurrence of invertebrate prey in age- 0 yellow perch stomach contents. Patchiness could lead age-0 yellow perch to use search behaviors effective at finding clusters of prey (Humphries et al., 2012). In diving predators, such as seals, patch quality and prey encounter rates are an important factor in the decision to forage on a patch of prey or continue to search (Thompson and Fedak, 2001). Likewise, it is likely that prey patchiness is an important factor in the prey and habitat choices made by age- 0 yellow perch.

\section{Methods}

Habitat selection of age-0 yellow perch was assessed at six locations along western Lake Michigan. Each study location consisted of one pair of sites, one rock and one sand. Western Lake Michigan's littoral habitat is composed of a mosaic of different rock, sand, and clay outcroppings (Janssen et al., 2005). Sampling locations were chosen for their proximity to both rock and sand substrates by analyzing aerial photographs of the coastline captured in 2005 . Promising locations determined from the photographs, were ground-truthed for suitable substrate type by wading, snorkeling, and scuba diving. Final study locations, from north to south, were: Sheboygan, Donges Bay, Fox Point, Whitefish Bay, Milwaukee, and Wind Point, a longitudinal distance of $112 \mathrm{~km}$ (Figure 1). Across the study locations, "rock" sites were composed of a range of different types of hard substrate consisting of bedrock (Silurian- 
dolomite limestone at Sheboygan and Wind Point and Devonian mudstone at Fox Point) and clay outcroppings overlain by glacial till ranging in size from cobble to boulders (the other three locations). "Sand" sites at all locations were composed almost entirely of sand deposited from coastal moraine bluffs, with only occasional rocks present. We could find no more than six suitable locations and the yellow perch population becomes scarce north of our most northern location, Sheboygan (Pradeep Hirethota, WI DNR, pers. comm.). The exact areal dimensions of rock patches was unknown because the aerial photographs were only effective to a depth of about 6-8 meters.

Habitat selection of age- 0 yellow perch was estimated using catch-per-unit-effort (CPUE) from micromesh gillnetting performed at each of the six study locations (replicates). Age-0 yellow perch and round gobies CPUEs were defined as the total number of each species captured in overnight gill net sets. Within each location one gill net was set at the rock site and one at the sand site, resulting in six pairs of gill-net samples per year (Figure 1). Pairs of rock and sand sites were within $5 \mathrm{~km}$ of each other (most within $1 \mathrm{~km}$ ). Gill net sets were performed in late August and early September, of 2006 and 2007. GPS coordinates for both ends of a net were recorded and the between year variation in study site position was generally less than $50 \mathrm{~m}$. Gill nets consisted of two panels, one $6 \mathrm{~mm}$ and one $8 \mathrm{~mm}$ bar monofilament. Each panel was $1.2 \mathrm{~m}$ high by $30-\mathrm{m}$ long ( $60 \mathrm{~m}$ total gill-net length). Similar gill nets are now used around Lake Michigan for yearly age- 0 yellow perch assessment, and are known to catch age-0 yellow perch and mid-sized round gobies (Diana et al. 2006; Janssen and Luebke, 2004) although it is possible that some small age one perch may have contributed to the catches. At shallow water 
locations (Sheboygan, Fox Point, Whitefish Bay, and Wind Point), gill nets were set in $\approx 1.5 \mathrm{~m}$ of water by wading from shore. These four locations had very large boulders or blocks of bedrock making operating from a power boat hazardous. Gill nets were set in $\approx 4 \mathrm{~m}$ depth at locations accessed by boat (Donges Bay and Milwaukee), nets were set in same water depths for each pair of sites. Gill nets were typically set within $\approx 1$ hour before sunset and pulled $\approx 1$ hour after sunrise the next morning (total soak time $\approx 12$ hours). Age-0 yellow perch and round gobies were immediately removed from the net upon retrieval and enumerated, captured fish were also preserved in ethanol for diet analysis.

Stomach content analysis was performed on age- 0 yellow perch and round gobies captured at rock sites, to assess diet similarity and diet shifts of age- 0 yellow perch where round gobies were present. Captured fish were picked from gill nets immediately after retrieval and live fish were euthanized in an overdose of MS-222. Fish were enumerated, labeled, and stored in $95 \%$ ethyl alcohol with their body cavities opened to allow quick and thorough saturation of the carcasses. Yellow perch up to $115 \mathrm{~mm}$ total length were considered age-0, comparable to the size range used in previous studies of age- 0 yellow perch in southwestern Lake Michigan (Marsden and Robillard, 2004). Few age-0 yellow perch captured in the micromesh gill nets were greater than $80 \mathrm{~mm}$ total length ( $16 \%$ of dissected fish). Standard lengths for age-0 yellow perch in the current study were similar to the $43-66 \mathrm{~mm}$ standard lengths from Janssen and Luebke (2004) and age-1 yellow perch lengths reported from 1984-2004 in southern Lake Michigan (Headley and Lauer, 2008). 
Stomach contents of age-0 yellow perch and round gobies were analyzed by removing the stomach and identifying its contents to the lowest practical taxon using a dissecting microscope. For round gobies we define the "stomach" as the entire digestive track as round gobies lack a defined stomach. Stomach content analysis was performed on subsamples of 10 age- 0 yellow perch and 10 round gobies from each rock site. If fewer than 10 individuals of each species were captured, all fish stomachs were analyzed. The total number of each prey taxon was tallied for individual age-0 yellow perch and round goby stomachs from all rock sites.

For both benthic invertebrate collections and stomach content analysis, individual taxa were identified to the lowest practical taxa and enumerated. Whole or partially digested prey items were counted for numerical abundance, including chironomid head capsules. Prey weight and volume were not estimated. Chironomid larvae and amphipods were singled out for further analysis due to their high abundance in age- 0 yellow perch and round goby stomach contents at rock sites, and because they were quantifiable in the environment using rock collections.

Chironomid larvae and amphipods are preferentially associated with rock substrates.

Therefore, the occurrence of chironomid larvae and amphipods in the stomach contents of age0 yellow perch is an important indicator of feeding on the benthos at rock habitats

To determine the effect of round goby presence on the benthic invertebrate community we collected rocks using similar methods to Lederer et al. (2006). Rock samples were collected by divers at each rock site prior to setting gill nets. Rock invertebrate collections consisted of a diver haphazardly retrieving a cobble-sized rock from the bottom with eyes closed, enveloping it in a cloth bag, and tying it shut. Five rocks of similar size were retrieved at each rock site. 
Rocks measured $\approx 20 \mathrm{~cm}$ along the longest axis. Bags were then brought to the surface and placed in a water-filled cooler for transit to the lab. In the lab, rocks were scraped clean onto a 3.5- $\mathrm{mm}$ screen to separate dreissenid mussels and other large invertebrates. The resulting filtrate was then washed through a $500-\mu \mathrm{m}$ sieve and remaining non-dreissenid invertebrates on both screens were enumerated under a dissecting microscope. Non-dreissenid invertebrates that remained on the large screen were added to the small invertebrate tallies.

In 2006 and 2007, round goby abundance estimates from gillnetting were supplemented with video strip transects conducted by scuba divers. Round goby abundance estimates using video strip transects were important for two reasons. First, they allowed us to relate relative abundance of round gobies at rock sites by comparing the two methods and visual estimates had been used previously by others (Diana et al. 2006, Ray and Corkum, 2001). Second, they allowed us to record the spatial variation of round goby densities within rock sites, which may have an effect on the round goby-yellow perch interaction. Video transects were completed by two scuba divers. One diver used a video camera in an underwater housing and recorded the transect, while the second diver aided in moving the transect line. The transect line was a $10 \mathrm{~m}$ long section of $\approx 10$ - $\mathrm{mm}$ diameter cotton line that was weighted at both ends and placed haphazardly (swimming with eyes closed) on the bottom by the divers. Transects were separated by at least $10 \mathrm{~m}$. The diver with the camera then swam above the transect line with the camera held $\approx 1 \mathrm{~m}$ (with a weighted line spacer) off the bottom facing down toward the substrate. The video covered a swath $\approx 1 \mathrm{~m}$ wide and to estimate densities $100 \%$ detection 
probability was assumed. Five transects were recorded at each site. In the lab, video transects were reviewed in slow motion, and round gobies were tallied for each transect. Round goby CPUE, from video transects (Video CPUE), was defined as the total number of round gobies observed in each transect.

\section{Statistical methods}

A paired t-test comparing mean round goby gill-net CPUE at rock sites was calculated to determine if the number of round gobies on rock sites increased between 2006 and 2007. Pairs consisted of each individual site between 2006 and 2007. To determine whether rock habitat use by age- 0 yellow perch was affected by round goby presence on rock sites (Hypothesis 1) we correlated the percentage of age-0 yellow perch present at rock habitat with round goby CPUE from gill nets on rock sites. Percentage of age- 0 yellow perch at rock habitats was used because we expect that the concept of the Ideal Free Distribution applies, i.e. fish will proportionately distribute themselves among the two habitats with respect to relative profitability of prey resources. A similar concept was applied to northern pike (Esox Lucius) in Lake Windermere, England (Haugen et al. 2006). Age-0 yellow perch in the current study were likely becoming demersal and therefore in the process of assessing the relative profitability of littoral habitats (Miehls and Dettmers, 2011).

Percentage of age- 0 yellow perch using rock habitat was calculated, for each location, by dividing age- 0 yellow perch CPUE from gill nets set at rock sites, by the total age- 0 yellow perch CPUE caught at both sites and multiplying by 100 . Round goby CPUE values were $\log _{10}+1$ 
transformed and percentage age-0 yellow perch rock habitat use values were arcsine square root transformed (Zar, 1999). Pearson's correlation coefficient ( $r$ ) was computed for 2006 and 2007 separately, because spatial observations were not independent between years. A temporally combined Pearson's correlation coefficient that included age-0 yellow perch habitat selection data from 2002 (Janssen and Luebke, 2004) and a preliminary sampling conducted in 2005 at Fox Point, Milwaukee, and Wind Point was also calculated. Janssen and Luebke (2004) performed sampling using identical methods in 2002 at four of our study locations before round gobies were present. The temporally combined correlation resulted in 20 different age- 0 yellow rock habitat use values from 2002 to 2007 . While this temporally combined correlation suggests an overall trend, due to issues of independence related to repeated sampling of same sites year after year, we do not report the significance level for this correlation.

Round goby CPUE from video transects was used to determine the spatial distribution of round gobies at rock sites. First, Pearson's correlation coefficient ( $r$ ) was calculated between mean video strip transect CPUE and micromesh gill-net CPUE at each site for 2006 and 2007 separately, to compare the similarity between video strip transect CPUE and micromesh gill-net CPUE. In 2006 and 2007, gill nets were set at the six sites resulting in 12 round goby gill-net CPUE estimates, with five video transects performed at each site and date. Index of Contagion (IoC, the variance to mean ratio, Elliot, 1971) for round goby video CPUE was then calculated for each site in 2006 and 2007, separately. Two, one sample t-tests were then run for loC values from each year to determine if the round goby loC values significantly differed from 1.0, a Poisson distribution. Index of contagion values close to 1.0 would indicate round gobies were 
distributed randomly and loC values greater than 1.0 would indicate round gobies were distributed in patches (Elliott, 1971, Steel and Torrie, 1980).

Hypothesis 2 was tested by calculating year specific Pearson's correlation coefficients between round goby gill-net CPUE and the mean of summed chironomid larvae and amphipods on individual rocks. Similarly, for hypothesis 3, separate correlation coefficients for 2006 and 2007 were calculated between round goby gill-net CPUE at rock sites and the mean of summed chironomid larvae and amphipods in age-0 yellow perch stomach contents at rock sites. All count data were $\log _{10}+1$ transformed. For both analyses, chironomid larvae and amphipods were summed because the biological question was whether yellow perch consumption of benthic prey was impacted by round goby density. Presumably a yellow perch searching among rocks will consume either chironomid larvae or amphipods, but, given prey patchiness we did not attempt to estimate relative selectivity for chironomid larvae or amphipods. A significant negative correlation may indicate round gobies decreased invertebrate prey availability at rock sites (for rock counts), and that round gobies negatively impact the feeding of age-0 yellow perch at rock habitats (for age-0 yellow perch stomach contents).

Index of contagion was also calculated for chironomid larvae and amphipods within rock sites to determine whether these prey occurred in patches, where variance among rocks within sites is much higher than the mean number of benthic invertebrates captured among rocks at a site. Year-specific one sample t-tests were then used to determine if chironomid larvae and amphipod loC values were significantly different than 1.0 among all sites in 2006 and 2007. 


\section{RESULTS}

The paired t-test comparing round goby gill-net CPUE at rock cites indicated round gobies increased in abundance from 2006 to $2007\left(t_{5}=-3.776, P=0.013 ;\right.$ Fig 2$)$, showing the invasion front of round gobies was captured during the study period.

The most abundant prey items in round goby gut contents in 2006 and 2007 were chironomid larvae (31\%), amphipods (17\%), and isopods (11\%). Age-0 yellow perch also consumed large numbers of chironomid larvae (41\%), amphipods (8\%), with fewer isopods (3\%) so prey overlap was primarily with chironomid larvae and amphipods. Chironomid pupae were also consumed by age-0 yellow perch (31\%) and round gobies (12\%). Chironomid pupae can occur on the bottom and throughout the water column, which make them ambiguous prey in regards to age0 yellow perch feeding strategy. Other prey were mainly zooplankton or drowned terrestrial insects, generally in relatively low numbers. Therefore, we focused our analyses on the relationship between round gobies, chironomid larvae and amphipods, both in the environment and in age-0 yellow perch gut contents to determine changes in habitat and prey use. A more complete description of rock benthic invertebrate abundance, age- 0 yellow perch and round goby stomach contents can be found in Houghton (2015).

In the environment, chironomid larvae and amphipods were abundant at all rock locations (Table 1). Index of contagion values in 2006 and 2007 were greater than 1.0 for both taxa at all locations (range 2.7 to 569.7) except Wind Point chironomid larvae in 2006 (loC = 0.3). However, t-tests indicated mean loC values were only significantly different than 1.0 (Poisson) for amphipods in $2006\left(t_{4}=3.313, P=0.030\right.$; for $\left.2007, t_{5}=1.810, P=0.130\right)$. Mean loC values 
for chironomid larvae were not significantly greater than 1.0, but were marginally significant in $2007\left(t_{5}=2.531, P=0.052 ;\right.$ for $\left.2006 t_{4}=1.512, P=0.205\right)$.

In 2007, there was a significant correlation between gill-net CPUE and mean video transect estimates of round goby $\left(r_{4}=0.895, P=0.016\right)$. However, in 2006 a significant correlation was not detected $\left(r_{4}=0.520, P=0.293\right)$. This could be due to low statistical power. Round gobies exhibited a distribution not distinguishable from Poisson in 2006 and 2007 . Mean loC for round goby CPUE from video transects at rock sites were not significantly different from 1.0 in either $2006\left(t_{4}=-2.256, P=0.087\right)$ or $2007\left(t_{3}=2.106, P=0.126\right)$.

There was a negative correlation between percent of age- 0 yellow perch collected via gill net on rock habitat versus round goby gill-net CPUE for both $2006\left(r_{4}=-0.94, P=0.005\right)$ and $2007\left(r_{4}=\right.$ $-0.87, P=0.025 ;$ Fig 3a). The correlation coefficients for the two years were not statistically distinguishable (using z-transformation of correlation coefficients as described by Zar (1999)). The temporally combined correlation that includes 2002 data from Janssen and Luebke (2004) and our preliminary 2005 data was consistent with observations in 2006 and $2007\left(r_{18}=-0.85\right)$.

The mean of summed amphipod and chironomid larvae collected on rocks for each site versus round goby gill-net CPUE also showed a strong negative relationship in $2007\left(r_{4}=-0.97, P\right.$ $=0.001 ;$ Fig 3b). We did not detect a correlation for 2006 , likely because round goby numbers were significantly lower the first year of the study. Correlation analysis also indicated negative relationships between the mean of summed amphipod and chironomid larvae in age-0 yellow perch stomachs contents versus round goby gill-net CPUE at rock sites in $2006\left(r_{3}=-0.92, P=\right.$ $0.026)$ and $2007\left(r_{3}=-0.92, P=0.027 ;\right.$ Fig 3c). 


\section{Discussion}

The three hypotheses tested, habitat shift by yellow perch, evidence of resource depression by round gobies, and diet shift by yellow perch are consistent with the broader hypothesis that round gobies may exert competitive pressure on newly demersal yellow perch. None of the field experiment components refutes the broad hypothesis.

Hypothesis 1, that preferred habitat of age-0 yellow perch has shifted away from rock substrates to sand substrates was supported by the strong negative correlation of round goby densities with percent yellow perch collected on rock habitat. It would, of course, be better to have a long time series of habitat selection by age- 0 yellow perch, but the use of micromesh gill nets is relatively recent and rock habitats have only recently been mapped for Wisconsin in enough detail to generate paired substrate types. Our subsequent explorations revealed no more potential sampling locations.

Hypothesis 3, that there was a diet shift for age-0 yellow perch correlated with increasing round goby density at rock habitats, was also supported in this study. At rock substrate sites, where round gobies were present, age-0 yellow perch fed less on chironomid larvae and amphipod prey. Over sand sites age-0 yellow perch may be preying on more zooplankton prey, however the data were only suggestive for one of the two years (Houghton, unpublished data). However, while not sampled due to logistical difficulties created by shallow water and rock habitat, zooplankton would have been available at both rock and sand sites whereas the other 
significant prey items, amphipods, isopods, and chironomids are primarily associated with rock habitat (Kornis and Janssen, 2011).

Correlation does not necessarily imply cause and effect because some third agent could be driving the response of both. However, evidence of an underlying mechanism does make it less likely that there is a third agent. The second hypothesis, that round gobies can depress food resources, was also supported by our analyses and provides a potential mechanism for the observed change in age-0 yellow perch habitat selection. Increased round goby densities at rock habitats decreased the abundance of key benthic invertebrate prey for age- 0 yellow perch: amphipods and chironomid larvae. A negative relationship between round gobies and the density of invertebrate prey across a round goby invasion front was also shown by Lederer et al. (2006).

It is very likely that we conducted insufficient rock sampling to adequately assess impacts of round gobies on potential prey. As is typical of rock habitat, invertebrates showed great contagion making statistical analyses difficult without extensive sampling (Elliot, 1971). However, the patchiness itself is biologically important because fish searching for prey are likely primarily searching for patches of prey. This can contribute to great variation among individuals in diet. Because we found statistically detectable effects on prey densities and yellow perch diets, a more extensive study of prey and fish micro-distribution may elucidate unknown interactions between round gobies and age-0 yellow perch.

Studies have shown that switching between feeding strategies is dependent on the relative profitability of those prey items to fish (Graeb et al., 2004; Wu and Culver, 1992). Graeb et al. 
(2004) showed that $20-\mathrm{mm}$ yellow perch selected for zooplankton while 40 - and 60 -mm yellow perch began to feed on benthic invertebrates in mesocosm experiments. They theorized that while 20-mm yellow perch were able to feed upon benthic invertebrates (chironomid larvae in their study) they likely continued to feed on zooplankton due to differences in relative foraging cost. Thus, the shift from zooplankton to benthic invertebrate prey is determined by foraging efficiency and energetic gain rather than simple prey availability (i.e. zooplankton prey availability decreases in later summer to the point of being inefficient to capture). Similarly, Wu and Culver (1992) found that 50-mm TL age-0 yellow perch would only shift to benthic prey if zooplankton abundance dropped below 50/L, and this can happen at a range of yellow perch sizes. This shift to benthic prey is then determined by loss of zooplankton in the water column. The tradeoff between foraging efficiency and energetic gain for age- 0 yellow perch in the current study was complicated by the presence of round gobies, and the general lack of zooplankton prey, especially large cladocerans preferred by age-0 yellow perch, in western Lake Michigan. It is likely that the observed habitat switch and continued reliance on zooplankton prey by age- 0 yellow perch larger than $50 \mathrm{~mm}$ is detrimental to their growth. While age-0 yellow perch may be able to take advantage of the inherent patchiness of prey at rock habitats by opportunistically preying on benthic invertebrates during rock habitat feeding excursions, the act of switching between foraging modes, benthic versus pelagic, can take time and it is difficult for fish to switch back and forth between foraging modes (Murdoch et al., 1975).

While our study provides evidence of resource depression, an alternative, but not necessarily mutually exclusive mechanism for habitat displacement is interference competition. This has been implicated in habitat shifts in sunfishes (Werner and Hall, 1977) and several salmonines 
(Fausch, 1998, Hindar et al. 1988, Jonsson et al. 2008), broader review in Ross (2013).

However, in Lake in Lake Erie mesocosms aggressive interactions were not significantly higher between small yellow perch and round gobies than with small yellow perch and congeners (Duncan et al, 2011).

Both exploitative and interference competition may affect mortality rates of age- 0 yellow perch. If one consequence of competition is decreased growth, then the smallest yellow perch may succumb to overwinter starvation, as Bystrom et al. (1998) found for Eurasian perch (Perca fluviatilis) competing with roach (Rutilus rutilus). Even without mortality due to starvation, direct mortality could be due to predation. For example, Rice et al. (1987) argued that predation on age-0 bloater would likely increase if the larvae grew too slowly, due to exploitative competition for zooplankton, to escape predation. In such a case there is a combined competition and predation effect. Competition and predation can also combine for interference competition. Quinn and Janssen (1989, Lake Michigan), Garvey et al. (1994, Wisconsin lakes), and Soderback (1994, European lakes) argued that less aggressive crayfish species were more vulnerable to predation because they are more likely to lose in competition for adequate shelter.

Assuming that round gobies do drive a habitat shift in age-0 yellow perch, the broader scale consequences are unclear. Our study was limited to Wisconsin waters which are predominantly rock (Janssen et al., 2005) and the western side of Lake Michigan tends to be colder due to upwellings (Beletsky and Schwab, 2001) and has many fewer tributaries. This combination of factors likely led to regional differences in growth of both age-0 and older yellow perch (Horns, 
2001), so the impact of round gobies could vary by region. We conclude by encouraging broadscale approaches to round goby yellow and perch interactions which will require significantly more detail on the distribution and biota of Lake Michigan's diverse nearshore habitats.

\section{Acknowledgements}

Many thanks go to Juliane Finn and Chris Malinowski for aiding with sample collection and processing. John Berges, Tim Ehlinger, David Jude, and Harvey Bootsma provided preliminary reviews and suggestions that were instrumental in the final paper. This work was funded in part by the University of Wisconsin Sea Grant Institute under a grant from the National Sea

Grant College Program, National Oceanic and Atmospheric Administration, U.S. Department of Commerce, and from the State of Wisconsin. Federal grant number NA06OAR4170011, project number R/AI-1. It was also funded in part by the National Oceanic and Atmospheric Administration, Federal Grant Number NA09NMF4630406.

\section{References}

Beletsky, D., Schwab, D.J., 2001. Modeling circulation and thermal structure in Lake Michigan: annual cycle and interannual variability. J. Geophys. Res. 106, 19745.

Byström, P., Persson, L., Wahlström, E., 1998. Competing predators and prey: juvenile bottlenecks in whole-lake experiments. Ecology 79, 2153-2167.

Chisolm, R. 2009. The ecology, economics, management of alien invasive species. In: The Princeton guide to ecology, in: S.A. Levin (Ed.), The Princeton guide to ecology. Princeton University Press, Princeton, NJ, pp. 731-739.

Crowder, L.B., 1986. Ecological and morphological shifts in Lake Michigan fishes: glimpses of the ghost of competition past. Env. Biol. Fish. 16, 147-157. 
Diamond, J.M., 1970. Ecological consequences of island colonization by southwest pacific birds, I. Types of niche shifts. Proc. Natl. Acad. Sci. U.S.A. 67, 529-36.

Diana, C.M., Jonas, J.L., Claramunt, R.M., Fitzsimons, J.D., Marsden, J.E., 2006. A comparison of methods for sampling round goby in rocky littoral areas. North Am. J. Fish. Manag. 26, 514-522.

Dubs, D., Corkum, L., 1996. Behavioral interactions between round gobies (Neogobius melanostomus) and mottled sculpins (Cottus bairdi). J. Great Lakes Res. 22, 838-844.

Duncan, J.M., Marschner, C.A., González, M.J., 2011. Diet partitioning, habitat preferences and behavioral interactions between juvenile yellow perch and round goby in nearshore areas of Lake Erie. J. Great Lakes Res. 37, 101-110.

Elliott, J.M. 1971. Some methods for the statistical analysis of samples of benthic invertebrates. Sci. Pub. 25. Freshwater Biol. Ass. Ambleside, Westmorland, UK. 144 p.

Fausch, K.D., 1998. Interspecific competition and juvenile Atlantic salmon (Salmo salar): on testing effects and evaluating the evidence across scales. Can. J. Fish. Aquat. Sci. 55, 218231.

Garvey, J.E., Stein, R. A., Thomas, H.M. 1994. Assessing how fish predation and interspecific prey competition influence a crayfish assemblage. Ecology, 532-547.

Grace, J., Wetzel, R., 1981. Habitat partitioning and competitive displacement in cattails (Typha): experimental field studies. Am. Nat. 118, 463-474.

Graeb, B.D.S, Dettmers, J.M., Wahl, D.H. 2004. Fish size and prey availability affect growth, survival, prey selection, and foraging behavior of larval yellow perch. Trans. Am. Fish. Soc. 133, 504-514.

Haugen, T.O., Winfield, I.J., Vollestad, L.A., Fletche, J.M., James, J.B., Stenseth, N.C. 2006. The ideal free pike: 50 years of fitness-maximizing dispersal in Windermere. Proc. R. Soc. B. $273,2917-2924$

Headley, H.C., Lauer, T.E., 2008. Density-dependent growth of yellow perch in Southern Lake Michigan, 1984-2004. N. Am. J. Fish. Manag. 28, 57-69.

Hindar, K., Jonsson, B., Andrew, J.H., Northcote, T.G., 1988. Resource utilization of sympatric and experimentally allopatric cutthroat trout and Dolly Varden charr. Oecologia. 74, 481491. 
Horns, W.H.H., 2001. Spatial and temporal variation in length at age and condition of yellow perch in southern Lake Michigan during 1986-1988. North Am. J. Fish. Manag. 21, 580591.

Houghton, C.J. 2015. Round goby-induced changes in young-of-year yellow perch diet and habitat selection. PhD. dissertation. University of Wisconsin-Milwaukee.

Humphries, N.E., Weimerskirch, H., Queiroz, N., Southall, E.J., Sims, D.W., 2012. Foraging success of biological Lévy flights recorded in situ. Proc. Natl. Acad. Sci. U. S. A. 109, 716974.

Janssen, J., Berg, M.B., Lozano, S.J., 2005. Submerged terra incognita: Lake Michigan's abundant but unknown rocky zones, in: Edsall, T., Munuwar, M. (Eds.), The Lake Michigan Ecosystem: Ecology, Health and Management. Ecovis World Mon. Ser., pp. 113-139.

Janssen, J., Jude, D.J., 2001. Recruitment failure of mottled sculpin Cottus bairdi in Calumet Harbor, Southern Lake Michigan, induced by the newly introduced round goby Neogobius melanostomus. J. Great Lakes Res. 27, 319-328.

Janssen, J., Luebke, M.A., 2004. Preference for rocky habitat by age-0 yellow perch and alewives. J. Great Lakes Res. 30, 93-99.

Jonsson, B., Jonsson, N., Hindar, K., Northcote, T. G., Engen, S. 2008. Asymmetric competition drives lake use of coexisting salmonids. Oecologia, 157(4), 553-560.

Jude, D.J., Reider, R.H., Smith, G.R., 1992. Establishment of Gobiidae in the Great Lakes Basin. Can. J. Fish. Aquat. Sci. 49, 416-421. J. Great Lakes Res. 37, 561-566.

Kornis, M.S., Janssen, J., 2011. Linking emergent midges to alewife (Alosa pseudoharengus) preference for rocky habitat in Lake Michigan littoral zones. J. Great Lakes. Res. 37, 561566.

Kornis, M.S., Mercado-Silva, N., Vander Zanden, M.J., 2012. Twenty years of invasion: a review of round goby Neogobius melanostomus biology, spread and ecological implications. J. Fish Biol. 80, 235-85.

Lauer, T.E., Allen, P.J., McComish, T.S., 2004. Changes in mottled sculpin and johnny darter trawl catches after the appearance of round gobies in the Indiana waters of Lake Michigan. Trans. Am. Fish. Soc. 133, 185-189. 
Lederer, A., Massart, J., Janssen, J., 2006. Impact of round gobies (Neogobius melanostomus) on dreissenids (Dreissena polymorpha and Dreissena bugensis) and the associated macroinvertebrate community across an invasion front. J. Great Lakes Res. 32, 1-10.

Marsden, J.E.E., Robillard, S.R., 2004. Decline of yellow perch in southwestern Lake Michigan, 1987-1997. North Am. J. Fish. Manag. 24, 952-966.

Matthews, W.J., 1998. Patterns in freshwater fish ecology. Chapman and Hall, New York.

Miehls, S.M., Dettmers, J.M., 2011. Factors influencing habitat shifts of age-0 yellow perch in southwestern Lake Michigan. Trans. Am. Fish. Soc. 140, 1317-1329.

Murdoch, W.W., Avery, S., Smyth, M.E., 1975. Switching in predatory fish. Ecology, 1094-1105.

Poos, M., Dextrase, A.J., Schwalb, A. N., Ackerman, J. D. (2010). Secondary invasion of the round goby into high diversity Great Lakes tributaries and species at risk hotspots: potential new concerns for endangered freshwater species. Biol. Invas. 12, 1269-1284.

Quinn, J.P., Janssen, J. 1989. Crayfish competition in southwestern Lake Michigan: a predator mediated bottleneck. J. Freshwater Ecol. 5, 75-85.

Ray, W.J., Corkum, L.D., 2001. Habitat and site affinity of the round goby. J. Great Lakes Res. 27, 329-334.

Rice, J.A., Crowder, L.B., Binkowski, F.P. 1987. Evaluating potential sources of mortality for larval bloater (Coregonus hoyi): starvation and vulnerability to predation. Can. J. Fish. Aquat. Sci. 44, 467-472.

Ross, S.T., 2013. Ecology of North American freshwater fishes. U. California Press, Berkeley.

Schoener, T., 1974. Resource partitioning in ecological communities. Science. 185, 27-39.

Schoener, T., 1975. Presence and absence of habitat shift in some widespread lizard species. Ecol. Monogr. 45, 233-258.

Schoener, T., 1983. Field experiments on interspecific competition. Am. Nat. 122, 240-285.

Söderbäck, B., 1994. Interactions among juveniles of two freshwater crayfish species and a predatory fish. Oecologia 100, 229-235.

Steel, R. G., Torrie, J.H., 1980. Principles and Procedures of Statistics: A Biometrical Approach. McGraw-Hill New York. 633 pp. 
Thompson, D., Fedak, M. A., 2001. How long should a dive last? A simple model of foraging decisions by breath-hold divers in a patch environment. Anim. Behav. 61, 287-296.

Wanink, J.H., Witte, F., 2000. The use of perturbation as a natural experiment: effects of predator introduction on the community structure of zooplanktivorous fish in Lake Victoria. Adv. in Ecol. Res. 31, 553-570

Werner, E.E., Hall, D.J. 1977. Competition and habitat shift in two sunfishes (Centrarchidae). Ecology. 58, 869-876.

Wu, L., Culver, D.A. 1992. Ontogenetic diet shift in Lake Erie age-0 yellow perch (Perca flavescens): a size-related response to zooplankton density. Can. J. Fish. Aquat. Sci. 49, 1932-1937

Zar, J.H., 1999. Biostatistical Analysis, 4th ed. Prentice Hall, Upper Saddle River, New Jersey 


\section{List of Figures}

Figure 1. Study locations for evaluating yellow perch-round goby interactions along the Wisconsin shoreline of Lake Michigan; Circles = Rock sites, Triangles = Sand Sites.

Figure 2. Scatterplot of Round Goby gill-net CPUE at six study sites in 2006 (circles) and 2007 (squares) versus study site distance from Milwaukee Harbor, the location of the initial round goby introduction. No round gobies were collected in either year at Wind Point. Paired t-test indicated round goby CPUE were significantly higher in 2007 than $2006\left(t_{5}=-3.776, P=0.013\right)$, showing the ongoing invasion front was captured during the study period.

Figure 3(a) Age-0 yellow perch rock habitat use versus round goby gill-net CPUE at all study sites in 2006 (circles) and 2007 (squares). Correlation analysis indicates a negative relationship in $2006\left(r_{4}=-0.94, P=0.005\right)$ and $2007\left(r_{4}=-0.87, P=0.025\right)$, separately. Pooling data from both years, preliminary data collected in 2005, and Janssen and Luebke's (2004; collected in 2002) data also shows a strong negative relationship $\left(r_{18}=-0.85, P=0.001\right)$. (b) The mean of summed amphipod and chironomid larvae collected on rocks for each site versus round goby gill-net CPUE also showed a strong negative relationship in $2007\left(r_{4}=-0.97, P=0.001\right)$.) (c) Correlation analysis also indicated a negative relationship between the mean of summed amphipod and chironomid larvae in age-0 yellow perch stomachs (number/ yp stomach) at each site versus round goby gill-net CPUE in $2006\left(r_{3}=-0.92, P=0.026\right)$ and $2007\left(r_{3}=-0.92, P=\right.$ 0.027 ). All count data were $\log _{10}+1$ transformed for analyses. 
Table 1. Mean $(\bar{x})$ number of chironomid larvae and amphipods found on rocks at each study location. Index of Contagion (IoC) for chironomid larvae and amphipod counts from rocks collected at six sites in western Lake Michigan in 2006 and 2007 (Five rocks were collected from each site; Fox Point 2006 excluded due to missing rocks).

\begin{tabular}{|c|c|c|c|c|c|c|c|c|c|c|c|c|c|}
\hline \multirow[b]{2}{*}{ Year } & \multirow[b]{2}{*}{ Taxa } & \multicolumn{2}{|c|}{ Sheboygan } & \multicolumn{2}{|c|}{ Donges Bay } & \multicolumn{2}{|c|}{ Fox Point } & \multicolumn{2}{|c|}{ Whitefish Bay } & \multicolumn{2}{|c|}{ Milwaukee } & \multicolumn{2}{|c|}{ Wind Point } \\
\hline & & $\overline{\mathrm{x}}$ & IoC & $\overline{\mathrm{x}}$ & IoC & $\overline{\mathrm{x}}$ & IoC & $\overline{\mathrm{x}}$ & IoC & $\overline{\mathrm{x}}$ & IoC & $\overline{\mathrm{x}}$ & IoC \\
\hline \multirow{2}{*}{2006} & Chironomid larvae & 33 & 4.9 & 33.4 & 569.6 & & & 9.6 & 260.8 & 23.6 & 12.4 & 38.3 & 0.3 \\
\hline & Amphipod & 26.6 & 26.3 & 155.6 & 33.2 & & & 89.6 & 11.3 & 25.6 & 17.6 & 34.5 & 3.6 \\
\hline \multirow[t]{2}{*}{2007} & Chironomid larvae & 91.2 & 6.6 & 47.4 & 6.8 & 146.0 & 58.4 & 55.4 & 32.5 & 21.2 & 7.0 & 230.2 & 22.6 \\
\hline & Amphipod & 31.0 & 7.5 & 18.0 & 8.8 & 15.8 & 64.8 & 8.8 & 11.9 & 25.0 & 4.6 & 89.8 & 10.6 \\
\hline
\end{tabular}




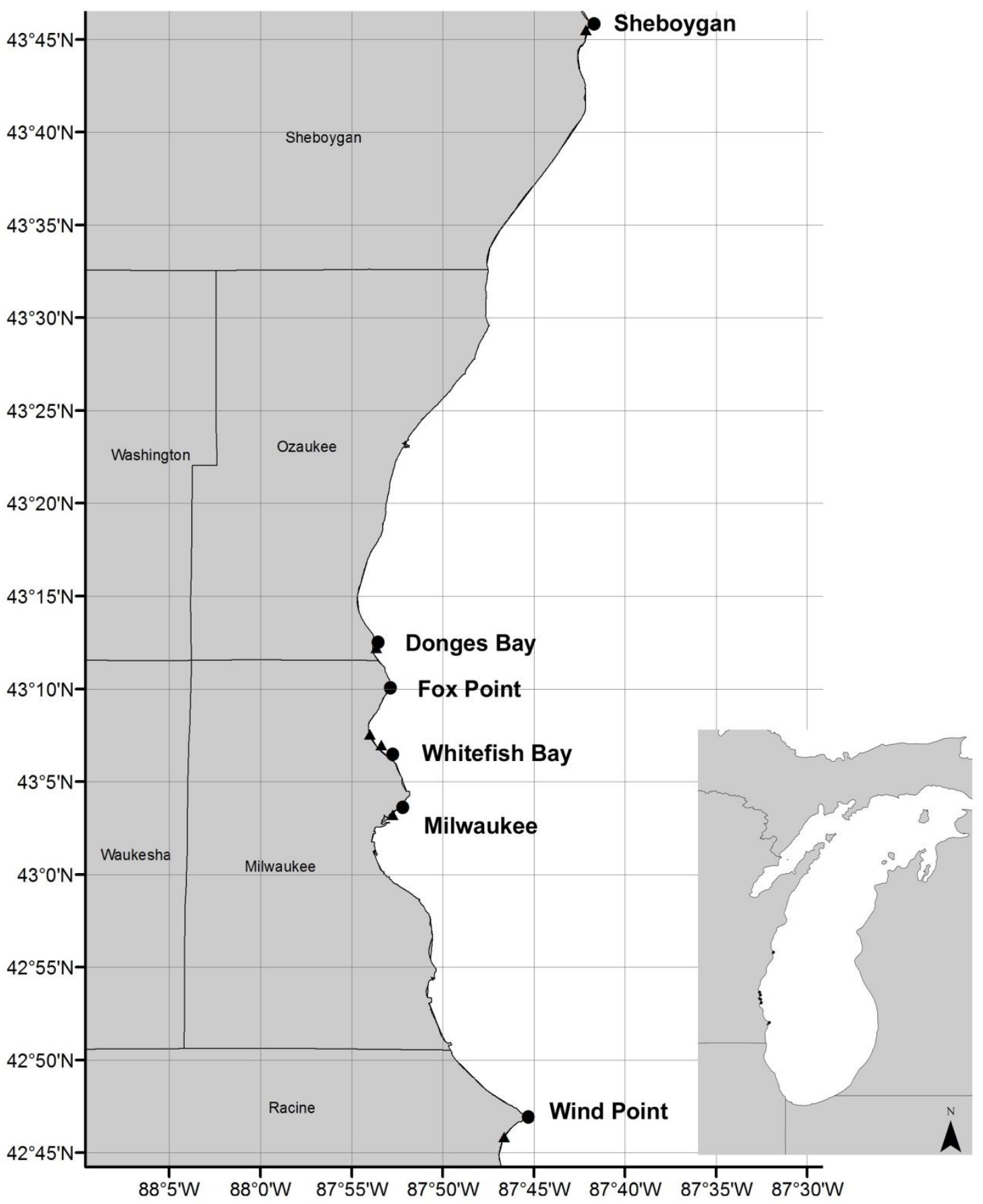

Figure 1 


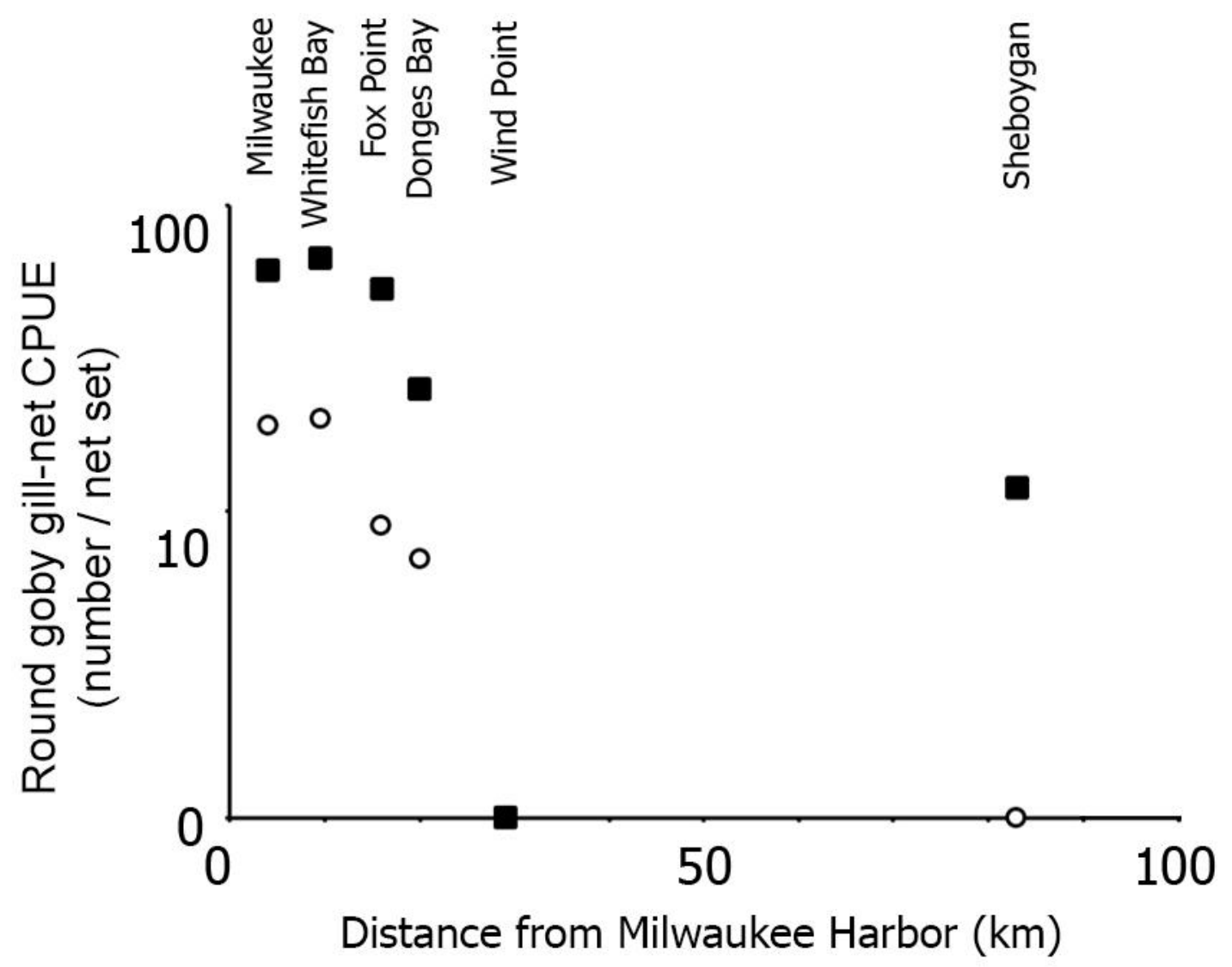

Figure 2 

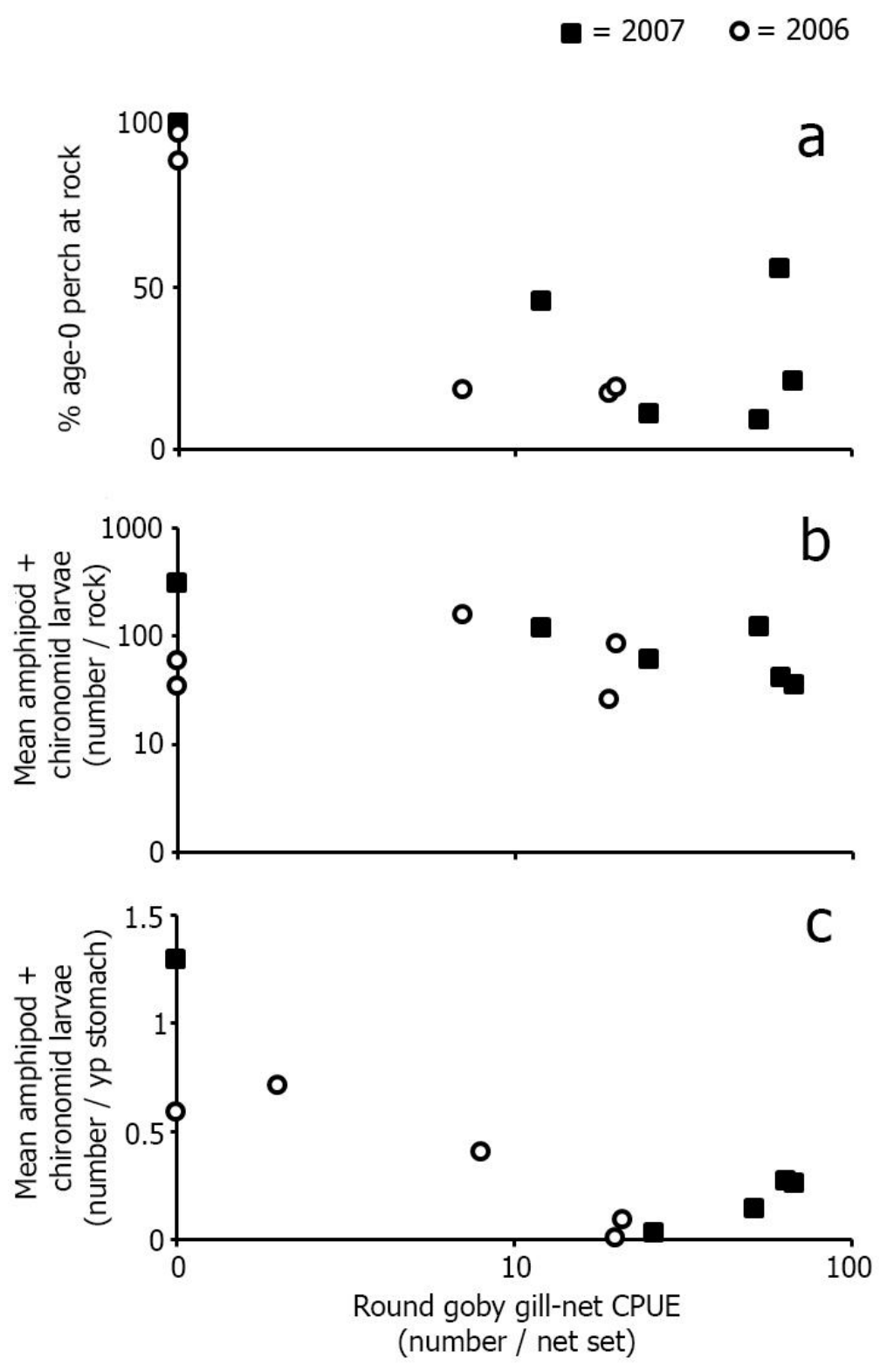

Figure 3 